\title{
I mproving clinical practice in the management of elderly patients hospitalized with antimicrobial resistant organisms
}

\author{
Natasha Antonio ${ }^{1}$, Louise Jensen ${ }^{2}$ \\ 1. Family Medicine, University of Alberta Hospital, Edmonton, Alberta, Canada. 2. Faculty of Nursing, University of Alberta, \\ Edmonton, Alberta, Canada.
}

Correspondence: Louise Jensen. Address: Faculty of Nursing, University of Alberta Hospital, Edmonton, Alberta, Canada. Email: louise.jensen@ualberta.ca

Received: October 31, 2013

Accepted: May 15, 2014

Online Published: June 3, 2014

DOI : $10.5430 /$ jnep.v4n8p107

URL: http://dx.doi.org/10.5430/jnep.v4n8p107

\begin{abstract}
Antibiotic resistant organisms (AROs) are commonly seen in elderly patients and have continued to grow in numbers over the past 10 years. Patients are isolated when hospitalized to prevent the spread of these pathogens. As a result, there are a number of negative psychological and physiological effects on elderly patients from being isolated. Isolation precautions have also affected provision of nursing care. Workplace and knowledge barriers preventing compliance with isolation protocols have been identified. The purpose of this literature review was to determine the impact of isolation due to AROs on hospitalized elderly patients and on nursing care and to provide recommendations to improve clinical practice and patient well-being.
\end{abstract}

\section{Key words}

Elderly, Hospital isolation, Impact of isolation, Microbial resistant organisms, Narrative review, Nursing elderly in isolation

\section{I ntroduction}

Methicillin Resistant Staphyloccocus Aureus (MRSA) and Vancomycin Resistant Enterococci (VRE) are the most commonly seen Antibiotic Resistance Organisms (AROs) among hospitalized patients. In 2011 the rate of hospital acquired MRSA was 1.39 cases per 1000 admissions in Canada ${ }^{[1]}$. The incidence of VRE in 2011 was 0.68 per 1000 patient admissions, a trend that has continued to rise ${ }^{[1]}$. The estimated number of illnesses and deaths caused by antibiotic resistance in the United States is 2,049,442 and 23,000, respectively ${ }^{[2]}$.

Patients 65 years of age or older represent 66\% of all adults identified with MRSA in hospitals from 1995-2002 ${ }^{[3]}$. In a surveillance of VRE among individuals in Canadian acute care hospitals, patients $60-79$ years represented $41.3 \%$ of the contaminated population and those greater than 80 years of age represented $32.2 \%$ of the population ${ }^{[4]}$. Generally, there is an increased risk of the elderly to acquire AROs, as they are more likely to have predisposing risk factors such as limited functional status and multiple co-morbidities. Thus, as the elderly population continues to grow, the number admitted to hospital with AROs will rise, with many being colonized. 


\section{The review}

\subsection{Aims}

With the ongoing presence of AROs in hospitals, patients screened positive for these organisms are isolated during hospital admission to prevent spread of infection and/or cross contamination. The need for contact precautions, while necessary, has a significant impact on hospitalized patients. The purpose of this literature review was to determine the impact of isolation on hospitalized elderly patients and the delivery of nursing care due to AROs, and to provide recommendations for geriatric nursing practice.

\subsection{Search methods}

Medline, Cumulative Index to Nursing and Allied Health Literature (CINAHL), Ovid EBMR Reviews, and Scopus databases were searched using the terms "elderly", "hospital isolation”, "contact isolation”, "impact of isolation”, "AROs" and "quarantine". The review was limited to articles in English, within the past 10 years, and if the population involved isolated hospitalized patients over 65 years of age, and/or identified limitations or recommendations for isolation precautions relating to AROs.

\subsection{Search outcomes}

A total of 28 articles were retrieved, with 14 articles identified that focused on the impact of isolation on hospitalized patients. Though only 4 articles specifically referred to an elderly population, a majority of the participants in the remaining 10 articles were over 65 years of age and identified the impact of isolation and/or recommendations for improvement.

\subsection{Quality appraisal and synthesis}

All 14 relevant articles meeting the inclusion criteria were included. As per a narrative review, population characteristics, context, and findings were reported to highlight the impact on and management strategies for elderly patients in isolation.

\section{Results}

\subsection{Prevention and control of antimicrobial resistant organisms}

Infection control guidelines stress the importance of hand hygiene, standard precautions, and contact precautions ${ }^{[5]}$. Routine screening for MRSA and VRE is completed upon admission to hospital for those with a history of AROs, hospitalization or institutionalization (i.e., long term care facilities) for 24-48 hours or more within the past 6 months ${ }^{[6]}$. Should contamination of a patient be suspected due to contact with an ARO positive roommate, swabs are completed and both patients are placed on isolation precautions.

Within the past few years, hospitals have adopted a more rigorous form of surveillance monitoring where all patients are swabbed once a week as routine, even if previously tested negative. The goal of strict monitoring is a preventative measure for potential ARO outbreaks, with results and trends monitored by infection control teams. In patients where colonization is present, without eminent wound or systemic infection, weekly cultures are discontinued and patients are tested monthly ${ }^{[6]}$.

The duration of isolation for patients treated for infection with an ARO, but who continue to be colonized with the organism at other body sites, remains an unresolved issue, as many remain colonized for long periods and surveillance cultures may fail to detect the organism's presence ${ }^{[5]}$. Decolonization therapy where topical and/or the use of systemic antimicrobial treatment is administered for the purpose of eradicating an ARO, have been used in high prevalence 
situations (i.e., control of outbreaks). However, lack of its efficiency and adverse events, such as antimicrobial resistance, does not warrant decolonization for routine use ${ }^{[6]}$.

Since there is a high potential for outbreaks with AROs, it is suggested that contact precautions be used indefinitely for all previously infected and known colonized patients for the duration of their hospital stay. Those who are successfully treated for a new ARO infection and test negative for 3 consecutive weeks may be taken off isolation precautions ${ }^{[6]}$. Follow up cultures resume weekly as per surveillance culture scheduling while the patient is hospitalized, and routine practices must be tailored to the characteristics of the patient and their environment.

\subsection{I solation impact on elderly patients}

Negative psychological and physiological effects on the isolated elderly patient have been documented. Negative physiological effects of isolation on elderly patients were the occurrence of preventable adverse events. Adverse events such as falls, malnutrition, the development of pressure ulcers, and fluid electrolyte imbalances were commonly reported as the result of a decrease in nursing and rehabilitation services, and increased length of hospital stay ${ }^{[7,8]}$.

Adverse psychological consequences included feelings of depression, anxiety, hostility, fear, loneliness, neglect, and low self-esteem ${ }^{[9,10]}$. These authors also report a sense of stigmatization, contamination, and imprisonment being described by elderly patients. The idea that being set apart from other ill individuals due to an antibiotic resistant organism increased overall psychological distress ${ }^{[11]}$. Overall, hospitalization is difficult for elderly patients and isolation due to AROs can further perpetuate an increase in psychological and physiological upset.

\subsubsection{I nadequate communication and information}

Many elderly patients were not satisfied with the communication accompanying the health care they received. They needed to understand their ARO diagnosis and valued having accurate information to enhance their knowledge and to better cope with their circumstances ${ }^{[12]}$. Major inconsistencies were noted in the information provided for AROs to patients and families. Mixed messages regarding ARO etiology, and reasons for the isolation protocol and ARO management, left patients feeling inadequately educated about why they are isolated and uncertain of the type of organism they are carrying ${ }^{[11,13]}$. Commonly, no written information for further reference was provided and no verbal information was given to elderly patients concerning which movement barriers apply, thus leading them to believe they were strictly confined to their room for the remainder of their hospital stay ${ }^{[14]}$. Feelings of stigmatization also occur when patients do not understand the reason for isolation. The use of gloves, gowns, and masks often led them to believe they are unclean and a danger to visitors ${ }^{[11]}$. Misinformed visitors were also reluctant to visit, with a fear of becoming contaminated.

Age related obstacles to understanding and learning information were also important factors. Sensory deficits such as hearing or sight loss, or chronic conditions such as dementia or depression, are especially prevalent in patients over 65 years of age, hindering understanding and interpretation of health information ${ }^{[15]}$. Knowledge was not consistently provided in terms that were clear and relatable to the elderly patient. These needs were possibly disregarded due to the preconceived notion by nurses that information will be forgotten or misinterpreted by the elderly patient regardless of the amount of time spent providing it. Staff attention to listening to the elderly patient was also found to be of poor quality. Elderly patients thought that if nursing staff took time to listen to what they had to say, more appropriate care and treatment would be provided and feelings of frustration and neglect reduced ${ }^{[14]}$.The rapidness with which isolation precautions are started also led to difficulty for elderly patients coming to terms with changes in their care. Elderly patients need careful preparation in order to cope appropriately ${ }^{[11]}$.

\subsubsection{Decreased attention and human contact}

Decreased attention from healthcare staff was identified as a problem with errors occurring in the process of care, such as incomplete vital signs or assessments, for elderly patients on isolation ${ }^{[9,11]}$. Nurses and physicians were found to spend approximately $22 \%$ less time with isolated patients and were two times less likely to enter the room at all ${ }^{[7]}$. Discussions 
among staff from the door way, long periods before answering call bells, and other service care errors were noted ${ }^{\text {[11] }}$, contributing to physiological adverse events. The occurrence of adverse events was seen $50 \%$ more often in isolated than non-isolated elderly patients due to less frequent patient monitoring and incomplete assessments and documentation by nursing staff ${ }^{[7]}$. Increased episodes of incontinence were also more prominent as a result of decreased contact between patient and nurse and spontaneous visits from staff, except for required tasks or when the call bell was pushed ${ }^{[11,16]}$.

While an isolation room offers privacy, solitude, and personal control, elderly patients found it limiting to their independence and social contacts ${ }^{[11,17]}$. Many attributed loneliness and anxiety to not only decreased attention from nursing staff, but lack of contact with visitors and other patients as well. Visitors who were uninformed regarding AROs or had no communication with nursing staff were more likely to visit less for fear of becoming contaminated ${ }^{[16]}$. Interaction with other patients was also next to none, causing feelings of imprisonment, boredom, and loneliness ${ }^{[14]}$. Elderly patients rely on interaction with other patients to put their own condition into perspective. As a result, those in isolation are often under the misconception that all the other patients in hospital are also confined to their room ${ }^{[12]}$.

Insufficient rehabilitation was also of concern to isolated elderly patients. Physical rehabilitation, occupational, and recreational therapies were observed to be lessened or absent for those with AROs ${ }^{[8]}$. The decrease or limitation of these services hindered improvement in the patient's functional status, consequently prolonging their hospital stay. While the wait for long term care placement can be lengthy, ARO positive patients experience on average an extra 10 days in hospital more than necessary ${ }^{[7]}$. Overall, elderly patients who are screened positive for AROs spend an average of 20 extra days in the hospital compared to those who are negative or colonized ${ }^{[8,17]}$.

\subsection{I mpact of isolation on delivery of nursing care}

The aim of isolation procedures is to control and minimize the spread of AROs. It is the responsibility of nursing staff and other health care workers to comply with isolation protocols to ensure cross contamination does not occur. Suboptimal compliance with isolation precautions still exists in many hospital settings and continues to exacerbate the probability of colonization or infection in elderly patients with resistant pathogens ${ }^{[18,19]}$. On average there is only a $73 \%$ compliance rate with contact isolation procedures in hospital ${ }^{[20,21]}$. Despite available resources, nurses were observed by isolated patients to be compliant with modes of precautions only $60 \%-70 \%$ of the time when entering an isolation room or when providing direct care ${ }^{[20,21]}$. As age and fragility already predispose elderly patients to a significant number of risk factors for contracting AROs, non-compliance with isolation precautions and poor hand hygiene increases the probability for ARO transmission. Barriers to isolation protocol compliance such as nurses' perceptions of AROs, knowledge deficiency, heavy patient caseloads, and hospital overcrowding affect the ability of nursing staff to deliver adequate patient care ${ }^{\text {[22-24] }}$.

\subsubsection{Perceptions}

Most nurses do not recognize AROs as a problem in their own institution, but rather perceived it to be a broader national concern ${ }^{[18]}$. Uncertainty of where patients contract AROs contributed to the reluctance of hospital staff to accept greater ownership of the problem as being caused by their own practices or care setting ${ }^{[25]}$. Uncertainties of where AROs are contracted create assumptions that elderly patients are being contaminated out in the community and bring it into the hospital ${ }^{[25]}$. Long term care (LTC) facilities serve as a reservoir for AROs which may spread into hospitals (8\%); however, recent hospitalization has been identified as a main risk factor for acquiring AROs among residents of LTC facilities $(70 \%)^{[3]}$.

\subsubsection{Knowledge}

Knowledge of AROs among nursing staff was often described as limited. Knowledge regarding principal reservoirs for AROs was inadequate and therefore increased exposure of health professionals to improper precautions and the risk of contamination and dissemination of these pathogens ${ }^{[22]}$. Nurses seek out knowledge if uncertain on how to manage a patient situation; however, lack of familiarity of where to find existing isolation protocols posed a barrier ${ }^{[23]}$. There was need for leadership and support to ensure more accessible educational information and staff training ${ }^{[25]}$. 
Nurses often did not feel confident in maintaining effective communication with patients ${ }^{[26]}$. Reluctance to share information and involve patients in decisions regarding their care existed. This may be because patients seek clarification as they become more informed about their treatment, making some staff uncomfortable ${ }^{[26]}$. Elderly patients and their families require effective communication to reduce feelings of stigmatization, frustration, stress, anxiety, and confusion ${ }^{[14]}$. Without staff educational support, patients were provided with little to no information regarding the purpose for isolation or the pathogen they carry and how it will be managed. Inadequate assessments also resulted, with patients being placed in isolation when they did not require it, or the development of preventable adverse events going unnoticed ${ }^{[7]}$.

\subsubsection{Workload}

Compliance with isolation precautions was greatly affected by nurses feeling stressed or fatigued. Such feelings were attributed to heavy patient care workloads, being short staffed, and overcrowding of patients ${ }^{[24,27]}$. The perceived imbalance of work in terms of available time or staff resources, forced nurses to prioritize care as best they could. Their time was divided among many patients and although nurses were aware of difficulties with isolation precautions, they had limited chance to address them ${ }^{[7,18]}$. Additionally, nursing staff take on duties unrelated to their field ${ }^{[27]}$. Many activities nurses classified as important may belong to the job description of other staff, such as running blood samples to the laboratory, filing medical reports, housekeeping duties and other patient monitoring roles ${ }^{[27]}$.

Nursing hand hygiene compliance changed under pressure and stress. Research shows nursing hand hygiene to be either carried out incorrectly $51.9 \%$ of the time or not done at all, $48.1 \%$ of the time ${ }^{[27]}$. The main source of cross transmission of AROs is at the hands of health care personnel ${ }^{[23]}$. Another hand hygiene barrier reported was skin irritation. Nursing staff did not have the time to properly dry their hands or hydrate their skin with lotions, and the constant use of alcohol rub, though more effective for eradicating certain pathogens, contributed to skin irritation even more ${ }^{[28]}$.

\subsubsection{Overcrowding}

Overcrowding of elderly patients significantly increased the prevalence of AROs and also sickness absence among staff. The prevalence of ARO infection was $41.7 \%$ in overcrowded wards compared to $25.1 \%$ in non-overcrowded wards ${ }^{\text {[24] }}$. Overcrowding of persons with dementia or confused elderly patients can be a challenge for nurses to manage. Demented or confused wandering patients were difficult to monitor and more likely to enter or leave isolation rooms without isolation attire. Also, the rate of ARO colonization is high in this cohort ${ }^{[24]}$. Patients colonized but not showing signs of visible infection may go undetected if they are not screened properly. The increased need for assistance with basic activities of daily living and other invasive procedures, posed a challenge to preventing ARO transmission because of close interpersonal contact ${ }^{[25]}$.

\section{Discussion}

It is clear there are negative psychological and physiological consequences with isolating elderly patients. Delivery of nursing care to these patients is also negatively affected. These findings reinforce the need for interventions aimed at improving knowledge and communication among staff and patients, increasing staff to patient ratios, and improving isolation protocol adherence and environments. Guidelines and recommendations for managing elderly patients with AROs are presented in Figure 1.

Nurses recognize the need for learning about and managing patients with AROs ${ }^{[29]}$. Educating nurses on ARO etiology, transmission, and management is the first step to changing staff attitudes and motivating improvement in practice ${ }^{[22]}$. Nurses become more aware of the importance of proper hand hygiene, isolation protocols, and how to assess and manage preventable adverse events and psychological upset that may occur in isolated elderly patients. Significant improvement in protocol adherence has been noted, with nurses being $71 \%$ more likely to remind staff about proper hand hygiene and contact precautions following education in-services ${ }^{[28]}$. 
Guidelines and Recommendations for Improving Clinical Practice in Managing Elderly Patients with AROs

\begin{tabular}{|c|c|}
\hline \multicolumn{2}{|c|}{ Is patient colonized or infected with an ARO? } \\
\hline \multicolumn{2}{|c|}{$\begin{array}{c}\text { Screening } \\
\text {-Swab nares, groin, rectum on admission and then weekly } \\
\text {-Other sites if present or infection suspected: ostomy } \\
\text { stoma, open wounds }\end{array}$} \\
\hline $\begin{array}{l}\text { Colonized } \\
\text { - No signs of active infection } \\
\text { Maintenance swabs as per site } \\
\text { protocol }\end{array}$ & $\begin{array}{l}\text { ARO Infection } \\
\text { - Signs of active infection } \\
\text { Swab weekly }\end{array}$ \\
\hline $\begin{array}{l}\text { - Cohort with other ARO colonized } \\
\text { patients } \\
\text { - Proper hand hygiene after } \\
\text { assisting patient with care } \\
\text { - Provide patient and family } \\
\text { information (verbal and written) } \\
\text { about ARO condition } \\
\text { - Colonization noted in patient chart } \\
\text { - Facility where patient is from } \\
\text { notified of ARO colonization } \\
\text { - Monitor for signs of active } \\
\text { infection } \\
\text { - Ensure patient receiving adequate } \\
\text { rehabilitation }\end{array}$ & $\begin{array}{l}\text { - Isolate with contact precautions and hand } \\
\text { hygiene } \\
\text { - Provide patient and family information (verbal } \\
\text { and written) about ARO condition and isolation } \\
\text { restrictions } \\
\text { - Colonization post resolved infection noted in } \\
\text { patient chart } \\
\text { - Facility where patient is from } \\
\text { notified of ARO infection } \\
\text { - Ensure patientreceiving adequaterehabilitation } \\
\text { - Provide access to phone, newspapers, TV } \\
\text { - Enable patient to leave their room by assisting } \\
\text { with isolation attire } \\
\text { - Monitor for new signs of infection } \\
\text { Monitor for signs of preventable adverse } \\
\text { events }\end{array}$ \\
\hline \multicolumn{2}{|c|}{$\begin{array}{l}\text { Recommendations } \\
\text { - Education in-services for nurses on ARO etiology, transmission and management } \\
\text { - Nursing staff are aware of where to locate information regarding AROs and } \\
\text { management protocols } \\
\text { - Nurses speak to unit manager when patient over crowding or workload is an issue } \\
\text { affecting isolation compliance and/ordelivery of patient care }\end{array}$} \\
\hline
\end{tabular}

Figure 1. Guidelines and recommendations for improving clinical practice in managing elderly patients with AROs

With the appropriate ARO training and education for nurses, written and verbal information can be provided to elderly patients and visitors prior to isolation precautions being put in place. Information should be provided in terms that are clear and relatable to the elderly patient. While there is little research on how elderly patients interpret or understand ARO information, the literature suggests they value active listening. By taking the time to actively listen, patients feel they are receiving better patient care, which reduces feelings of neglect, frustration, isolation, and anxiety ${ }^{[14,15]}$. Further research is also needed on efficient and effective teaching methods about AROs for elderly patients.

In order to allocate attention towards isolated patients and ARO management, there needs to be an increase in nursing staff. Higher nursing to patient ratios have been correlated with more rapid discharge, fewer ARO infections, and promotion of health among hospital staff ${ }^{[7,24]}$. It is also suggested that nurses have more time to focus on nursing care activities by delegating non-care activities to other allied and non-healthcare workers ${ }^{[27]}$. Activities such as transporting blood work or filing paperwork can be allocated, allowing nurses more time to concentrate on direct patient care.

Environmental surroundings largely influence the wellbeing of elderly patients in isolation. Feelings of boredom and imprisonment can be reduced by providing a window with a view, encouraging visitors to visit, and providing a common room whenever possible ${ }^{[14]}$. Establishing open communication and regular visit times with family and friends enables 
patients to feel connected to life outside their room ${ }^{[12]}$. Elderly patients who are colonized without signs of infection do not need to be isolated on their own, thus cohorting these patients could reduce the experience of confinement and claustrophobia ${ }^{[14,30]}$. Nursing staff need to differentiate between colonized and infectious patients, as $70 \%-80 \%$ of patients with AROs are over 65 years old and more likely to be asymptomatically colonized with an organism for prolonged periods without infection ${ }^{[3,31]}$. The value of contact with other patients is seen as a source of comfort among elderly patients, as it helps to put their own condition into perspective ${ }^{[14,31]}$. Other recommendations include providing patients access to telephones, books and newspapers, and ensuring that rehabilitation, occupational and recreational therapy are equally available to these individuals ${ }^{[11]}$. Thus, promoting education of staff, information redistribution among patients and families, and supportive isolation environments may help target the negative impact of isolation on elderly patients and inadequate delivery of nursing care.

\section{Conclusion}

Successful prevention and control strategies are required to reduce transmission of AROs. The elderly patient is especially vulnerable to the impact of AROs and isolation. A process put in place with adequate resources can help to reduce ARO burden and achieve positive patient and nursing outcomes.

\section{References}

[1] Public Health Agency of Canada. Antimicrobial Resistant Organisms (ARO) Surveillance - Surveillance Report for Data from January 1, 2007 to December 31, 2011.

[2] U.S. Department of Health and Human Services. Centers for Disease Control and Prevention. Antibiotic Resistance Threats in the United States. 2013.

[3] Simor AE, Ofner-Agostini M, Paton S, McGeer A, Loeb M, Bryce E, et al. Canadian Nosocomial Infection Surveillance Program. Clinical and epidemiologic features of methicillin-resistant Staphylococcus aureus in elderly hospitalized patients. Infection Control and Hospital Epidemiology: The Official Journal of the Society of Hospital Epidemiologists of America. 2005; 26: 838-841. PMid:16276960 http://dx.doi.org/10.1086/502503

[4] Public Health Agency of Canada.The Canadian Nosocomial Infection Surveillance Program. Surveillance for Vancomycin Resistant Enterococci (VRE) in Patients Hospitalized in Canadian Acute-Care Hospitals Participating in CNISP 2006 Results. 2008.

[5] Siegel JD, Rhinehart E, Jackson M, Chiarello L, Healthcare Infection Control Practices Advisory Committee. Management of multidrug-resistant organisms in health care settings, 2006. American Journal of Infection Control. 2007; 35(10 Suppl 2): S165-93. PMid:18068814 http://dx.doi.org/10.1016/j.ajic.2007.10.006

[6] Alberta Health and Wellness. Standards for prevention and management of Methicillin-Resistant Staphylococcus Aureus. 2008.

[7] Morgan DJ, Diekema DJ, Sepkowitz K, Perencevich EN. Adverse outcomes associated with Contact Precautions: a review of the literature. American Journal of Infection Control. 2009; 37: 85-93. PMid:19249637 http://dx.doi.org/10.1016/j.ajic.2008.04.257

[8] Morrison L, Stolarek I. Does MRSA affect patient outcomes in the elderly? A retrospective pilot study. The Journal of Hospital Infection. 2000; 45: 169-171. PMid:10860695 http://dx.doi.org/10.1053/jhin.2000.0727

[9] Abad C, Fearday A, Safdar, N. Adverse effects of isolation in hospitalised patients: A systematic review. The Journal of Hospital Infection. 2010; 76: 97-102. PMid:20619929 http://dx.doi.org/10.1016/j.jhin.2010.04.027

[10] Tarzi S, Kennedy P, Stone S, Evans M. Methicillin-resistant Staphylococcus aureus: Psychological impact of hospitalization and isolation in an older adult population. The Journal of Hospital Infection. 2001; 49: 250-254. PMid:11740872 http://dx.doi.org/10.1053/jhin.2001.1098

[11] Jones D. How to reduce the negative psychological impact of MRSA isolation on patients. Nursing Times. 2010; $106:$ 1-7.

[12] Barratt R, Shaban R, Moyle W. Behind barriers: patient's perceptions of source isolation for Methicillin-resistant Staphylococcus aureus (MRSA). Australian Journal of Advanced Nursing. 2010; 28: 53-59.

[13] Gasink LB, Singer K, Fishman NO, Holmes WC, Weiner MG, Bilker WB, Lautenbach E. Contact isolation for infection control in hospitalized patients: Is patient satisfaction affected? Infection Control and Hospital Epidemiology : The Official Journal of the Society of Hospital Epidemiologists of America. 2008; 2: 275-278. PMid:18205528 http://dx.doi.org/10.1086/527508 
[14] Ward D. Clinical infection control: reducing the psychological effects of isolation. British Journal of Nursing. 2000 ; 9: 162. PMid:11033629

[15] Benbow SM. Older people, mental health and learning. International Psychogeriatrics. 2009; 2: 799-804. PMid:19368759 http://dx.doi.org/10.1017/S1041610209009053

[16] Skyman E, Sjostrom HT, Hellstrom L. Patients' experiences of being infected with MRSA at a hospital and subsequently source isolated. Scandinavian Journal of Caring Sciences. 2010; 24: 101-107. PMid:20070592 http://dx.doi.org/10.1111/j.1471-6712.2009.00692.x

[17] Lucet JC, Grenet K, Armand-Lefevre L, Harnal M, Bouvet E, Regnier B, et al. High prevalence of carriage of methicillin-resistant Staphylococcus aureus at hospital admission in elderly patients: Implications for infection control strategies. Infection Control and Hospital Epidemiology: The Official Journal of the Society of Hospital Epidemiologists of America. 2005; 26: 121-126. PMid:15756880 http://dx.doi.org/10.1086/502514

[18] Giblin TB, Sinkowitz-Cochran RL, Harris PL, Jacobs S, Liberatore K, Palfreyman M A, et al. Clinicians' perceptions of the problem of antimicrobial resistance in health care facilities. Archives of Internal Medicine. 2004; 164: 1662-1668. PMid:15302636 http://dx.doi.org/10.1001/archinte.164.15.1662

[19] Halcomb EJ, Griffiths R, Fernandez R. The role of patient isolation and compliance with isolation practices in the control of nosocomial MRSA in acute care. International Journal of Evidence Based Healthcare. 2008; 6: 206-224. PMid:21631821

[20] Manian FA, Ponzillo JJ. Compliance with routine use of gowns by healthcare workers (HCWs) and non-HCW visitors on entry into the rooms of patients under contact precautions. Infection Control and Hospital Epidemiology: The Official Journal of the Society of Hospital Epidemiologists of America. 2007; 28: 337-340. PMid:17326026 http://dx.doi.org/10.1086/510811

[21] Weber DJ, Sickbert-Bennett E, Brown VM, Brooks RH, Kittrell IP, Featherstone BJ, et al. Compliance with isolation precautions at a university hospital. Infection Control \& Hospital Epidemiology. 2007; 28: 358-361. PMid:17326031 http://dx.doi.org/10.1086/510871

[22] de Moura J, Gir E. Nursing staff knowledge of multi-resistant bacterial infections. Acta Paulista De Enfermagem. 2007; 20: 351-356. http://dx.doi.org/10.1590/S0103-21002007000300018

[23] Mamhidir AG, Lindberg M, Larsson R, Flackman B, Engstrom M. Deficient knowledge of multidrug-resistant bacteria and preventive hygiene measures among primary healthcare personnel. Journal of Advanced Nursing. 2011; 67: 756-762. PMid:21198802 http://dx.doi.org/10.1111/j.1365-2648.2010.05533.x

[24] Virtanen M, Terho K, Oksanen T, Kurvinen T, Pentti J, Routamaa M, et al. Patients with infectious diseases, overcrowding, and health in hospital staff. Archives of Internal Medicine. 2011; 171: 1296-1298. PMid:21788550 http://dx.doi.org/10.1001/archinternmed.2011.313

[25] Morrow E, Griffiths P, Rao GG, Flaxman D. "Somebody else's problem?" Staff perceptions of the sources and control of meticillin-resistant Staphylococcus aureus. American Journal of Infection Control. 2011; 39: 284-291. PMid:21030114 http://dx.doi.org/10.1016/j.ajic.2010.06.018

[26] Duncan CP, Dealey C. Patients' feelings about hand washing, MRSA status and patient information. British Journal of Nursing. 2007; 16(1): 34-38. PMid:17353833 http://dx.doi.org/10.12968/bjon.2007.16.1.22713

[27] Knoll M, Lautenschlaeger C, Borneff-Lipp M. The impact of workload on hygiene compliance in nursing. British Journal of Nursing. 2010; 19(16): S18-22. PMid:20852459 http://dx.doi.org/10.12968/bjon.2010.19.Sup6.78213

[28] Burkitt KH, Sinkowitz-Cochran RL, Obrosky DS, Cuerdon T, Miller LJ, Jain R, Fine MJ. Survey of employee knowledge and attitudes before and after a multicenter Veterans' Administration quality improvement initiative to reduce nosocomial methicillin-resistant Staphylococcus aureus infections. American Journal of Infection Control. 2010; 38: $274-282$. PMid:20137828 http://dx.doi.org/10.1016/j.ajic.2009.08.019

[29] Easton PM, Sarma A, Williams FL, Marwick CA, Phillips G, Nathwani D. Infection control and management of MRSA: assessing the knowledge of staff in an acute hospital setting. The Journal of Hospital Infection. 2007; 66(1): 29-33. PMid:17316895 http://dx.doi.org/10.1016/j.jhin.2006.12.016

[30] Gilroy S, Stahl BM, Noonan C, Susman R, Lynette Johnson M, Kullman M, et al. Reduction of hospital-acquired methicillin-resistant staphylococcus aureus infection by cohorting patients in a dedicated unit. Infection Control and Hospital Epidemiology. 2009; 30: 203-205. PMid:19146466 http://dx.doi.org/10.1086/593968

[31] Tisinger CK. Empowering your patients in the fight against methicillin-resistant Staphylococcus aureus. Journal of the American Academy of Nurse Practitioners. 2008; 20: 204-211. PMid:18387017 http://dx.doi.org/10.1111/j.1745-7599.2007.00291.x 